\title{
Efficacy of Bloodletting Therapy in Patients with Chronic Idiopathic Urticaria: A Randomized Control Trial
}

\author{
Biru Ma (D, ${ }^{1,2}$ Xiuhua Chen, ${ }^{1}$ Yudan Liang, ${ }^{3}$ Weiquan Ouyang, ${ }^{2}$ Boyan Tang, ${ }^{4}$ Fanqi Meng, ${ }^{5}$ \\ Xiaohong Quan, ${ }^{6}$ Cong Wang, ${ }^{1}$ Ying Li, ${ }^{1}$ and Dacan Chen ${ }^{2}{ }^{2}$ \\ ${ }^{1}$ Traditional Therapy Clinic, The Second Clinical College of Guangzhou University of Chinese Medicine, \\ Guangzhou 510120, China \\ ${ }^{2}$ Dermatology Department, The Second Clinical College of Guangzhou University of Chinese Medicine, Guangzhou 510120, China \\ ${ }^{3}$ Department of Rehabilitation Medicine, Jiangmen Wuyi Hospital of Traditional Chinese Medicine, Jiangmen 529099, China \\ ${ }^{4}$ Cardiovascular Department, The Second Clinical College of Guangzhou University of Chinese Medicine, \\ Guangzhou 510120, China \\ ${ }^{5}$ Department of TCM Dermatology, Dermatology Hospital of Southern Medical University, Guangzhou 510095, China \\ ${ }^{6}$ Department of Rehabilitation Medicine, Peking University Shenzhen Hospital, Shenzhen 518035, China
}

Correspondence should be addressed to Dacan Chen; 4910702@163.com

Received 24 July 2020; Revised 1 September 2020; Accepted 19 September 2020; Published 30 October 2020

Academic Editor: Zhaohui Liang

Copyright (C) 2020 Biru Ma et al. This is an open access article distributed under the Creative Commons Attribution License, which permits unrestricted use, distribution, and reproduction in any medium, provided the original work is properly cited.

Objective. To assess the efficacy of bloodletting therapy (acupoint pricking and cupping) in patients with chronic idiopathic urticaria (CIU) in a randomized, control, parallel-group trial. Methods. A total of 174 patients with CIU enrolled from March 2018 to October 2019 were randomized into three groups: group A treated with bloodletting therapy and ebastine, group B treated with placebo treatment (acupoint pseudopricking and cupping) and ebastine, and group C treated with ebastine only. The intention-totreat analysis was conducted, and the primary outcome was the effective rate of UAS7 score being reduced to 7 or below after treatment phase. Results. The effective rates at the end of treatment phase were different among the three groups $(P<0.05)$, which were $73.7 \%$ in group A, $45.6 \%$ in group B, and $42.9 \%$ in group C. Multiple analysis indicated differences between groups A and B $(P<0.0125)$ and groups $\mathrm{A}$ and $\mathrm{C}(P<0.0125)$ and no difference between groups B and $\mathrm{C}(P>0.0125)$. No severe bloodletting therapy-related adverse events were observed. Conclusions. In this study on patients with CIU, one month of bloodletting therapy combined with ebastine is clinically beneficial compared with placebo treatment combined with ebastine and treatment with ebastine only. Thus, bloodletting therapy can be an effective complementary treatment in CIU. This trial is registered with ChiCTR1800015294.

\section{Introduction}

Chronic idiopathic urticaria, CIU (also known as chronic spontaneous urticaria in recent years), is defined by the appearance of wheals, angioedema, or both for $\geq 6$ weeks due to unknown causes [1]. Chronic urticaria affects about $0.5-1 \%$ of the population, and nearly $25 \%$ suffers from urticaria at least once during the lifetime [2]. CIU significantly affects the objective functioning and subjective well-being [3-5], resulting in substantial economic burden to patients and society because of its high direct and indirect healthcare costs $[3,6,7]$. The pathogenesis appears to be persistent activation of mast cells in the skin; however, the precise mechanism of mast cell triggering is yet unclear.

The main-stream treatment of CIU targets complete symptom control and modern second-generation $\mathrm{H} 1$-antihistamines constitute the first line treatment [1]. However, a meta-analysis reported that the rate of response to standard doses of antihistamine in CIU patients is 38.6\% (95\% CI 34.7-42.7) [8], similar to that reported more than a decade ago [9]. Moreover, sedation and impaired psychomotor 
function is reduced with second-generation antihistamines, but it can still occur. [10].

The possibility of a causal influence of emotional distress, especially of stressful life events, on the course of skin diseases has long been postulated [11]. Urticaria and angioedema can lead to significant stress and the converse is also recognized. Acute psychological stress may induce $\mathrm{CRH}$-dependent (corticotropin-releasing hormone) mast cell degranulation [12], and stress-related mechanisms may provide links to CIU [13-15]. Although psychological stress in isolation is unlikely to be the sole trigger, a high frequency of patients with CIU report a stressful event preceding the onset of CIU [16], and patients with CIU experience high rates of anxiety, depression, and somatoform disorders such as fibromyalgia, with half of subjects with CIU being affected by at least one of these conditions [17, 18]. Psychiatric comorbidity appears to significantly increase life quality impairment [19]. Bloodletting therapy is defined as the practice of treating diseases through the removal of a small amount of blood from patients at specific acupoints, collaterals with blood stasis or diseased regions. It has been used since primitive society in China and developed throughout the history of Chinese medicine. Bloodletting therapy has been proved effective in the treatment of generalized anxiety disorder [20], which leads us to speculate the positive influence of this treatment on the stress status of CIU patients and symptom improvement.

Traditional Chinese medicine has a long history in the recognition, identification, and administration of urticaria, which can be traced back to Huangdi Neijing (The Yellow Emperor's Internal Canon of Medicine) [21]. The clinical feature of urticaria with wheals and pruritus coming and going quickly is the manifestation of wind-evil that lurks in and circulates with blood. Hence, in the treatment of urticaria, dispersing wind is the one of the principle methods, and treating blood before wind is an important procedure because when blood flows fluently, wind-evil will resolve spontaneously. Bloodletting therapy is a direct and effective way of regulating blood. It has the potential of being an effective control in chronic urticaria, but the quality of present evidence is low [22-26].

Thus, we designed this randomized controlled trial with appropriate outcome measurements and long-term followup, aiming to provide convincing proof for this therapy in the treatment of CIU.

\section{Materials and Methods}

2.1. Participants. We recruited CIU patients from the dermatological clinic and the traditional therapy clinic of Guangdong Provincial Hospital of Chinese Medicine (Dade Road General Hospital) via posters and communication media, from March 2018 to October 2019. The diagnostic criteria were in reference to that of chronic spontaneous urticaria, according to the EAACI/GA2 LEN/EDF/WAO Guidelines (2013) [1]. The inclusion criteria were as follows: age: $18-70$ years; urticaria activity score (UAS7) $\geq 28$; subsequent regular visits. We excluded patients having the disease for $\geq 2$ years; patients who had taken antihistamines within three days and corticosteroids, nonsteroidal antiinflammatory drugs, or immunosuppressive drugs within one month before enrollment. The autologous serum skin test (ASST) [1] was performed to discern autoimmune urticaria. The eligibility criteria are listed in Table 1.

2.2. Sample Size Calculation. A preliminary test showed the effective rate of bloodletting therapy combined with ebastine in treating CIU was $76.8 \%$, and it has been reported that the effective rate of ebastine is $42.9 \%$ [27]. Herein, we needed 48 participants in each group to detect the difference between two samples (Stata/MP 13.1, $\alpha=0.5,1-\beta=0.90$ ). We added $20 \%$ to allow for dropouts and, thus, planned to include 58 participants in each group. The total sample size was determined as 174 for the three groups.

2.3. Randomization, Masking, and Procedures. Random cards were made and placed in an envelope by specialized staff according to the allocation sequence created using Stata/MP 13.1. Eligible patients were allocated to different groups in the order of the envelope sequence numbers. Except for the therapists, all the other staff and patients were unaware of the assignment groups during data collection.

2.4. Intervention. All three groups were prescribed ebastine tablets (Kastine, Industrias Farmaceuticas Almirall, S.A., Import Drug License No. H20140855) $10 \mathrm{mg} / \mathrm{d}, 28$ days. Patients in group A were treated additionally with bloodletting therapy (acupoint pricking and cupping), twice a week for four weeks. Patients in group B were given extra placebo treatment (acupoint pseudopricking and cupping), twice a week for four weeks.

2.5. Bloodletting Therapy (Acupoint Pricking and Cupping). Acupoints: Danshu (BL19, bilateral), Geshu (BL17, bilateral). After locating the acupoints, the therapist sterilized the skin and pricked three times on each acupoint with a disposable blood collection needle (SteriLance, Suzhou SteriLance Medical Device Co., Ltd.). All three pricks should be performed precisely within $1 \mathrm{~mm}$ to the exact acupoint location. Then, cupping was performed on the pricked acupoints and removed after $5 \mathrm{~min}$. The skin was cleaned and sterilized at the end of the treatment. The volume of the blood let out should be controlled around $1 \mathrm{~mL}$ per acupoint.

2.6. Placebo Treatment (Acupoint Pseudopricking and Cupping). Acupoints: Danshu (BL19, bilateral), Geshu (BL17, bilateral). The procedure was exactly the same as that of group A, but the handle of an ordinary acupuncture needle was used instead, and the handle head was gently pricked to make the patient feel the stimulation without piercing the skin.

2.7. Outcomes and Data Collection. In this trial, the primary outcome was the effective rate of UAS7 being reduced to 7 or below after treatment phase. The UAS is based on the assessment of key urticaria symptoms (wheals and pruritus). 
TABLe 1: | Eligibility criteria.

\begin{tabular}{|c|c|}
\hline Eligibility criteria & Details \\
\hline $\begin{array}{l}\text { Diagnostic } \\
\text { criteria }\end{array}$ & $\begin{array}{l}\text { Spontaneous wheals and/or angioedema }>6 \text { weeks; } \\
\text { Average wheal duration }<24 \mathrm{~h} \text {; } \\
\text { Exclusion of physical urticaria and other chronic urticaria types. }\end{array}$ \\
\hline Inclusion criteria & $\begin{array}{l}\text { Age } 18-70 \text { years; } \\
\text { Wheals and pruritus present almost daily, UAS7 } \geq 28 \text {; } \\
\text { Regular subsequent visits. }\end{array}$ \\
\hline Exclusion criteria & $\begin{array}{l}\text { Usage of antihistamines within three days or corticosteroids, nonsteroidal anti-inflammatory drugs, and } \\
\text { immunosuppressive drugs within one month before inclusion; } \\
\text { Course of disease }>2 \text { years; } \\
\text { Autoimmune urticaria; } \\
\text { Autoimmune diseases; } \\
\text { Allergic to ebastine; } \\
\text { Pregnant or breast-feeding women; } \\
\text { Thrombocytopenia and coagulation disturbance; } \\
\text { Abnormal liver and kidney function; } \\
\text { Trauma/infection; } \\
\text { Accompanied by fever, dizziness, headache or vomiting; } \\
\text { Cardiovascular and cerebrovascular disease, diabetes, kidney disease, abnormal bone metabolism, and acute attack of } \\
\text { asthma; } \\
\text { Mental disorder; } \\
\text { Ulcer, infection, or scar on treated skin; } \\
\text { Mistakenly enrolled; } \\
\text { Intermittent treatment; } \\
\text { Dropout or withdrawal voluntarily. }\end{array}$ \\
\hline
\end{tabular}

The UAS score ranges from 0-6. High score indicates severe activity of urticaria. As urticaria symptoms frequently change in intensity, the overall disease activity is best measured by advising patients to document $24 \mathrm{~h}$ self-evaluation scores for several days. UAS7 is the accumulation of UAS scores (0-42) self-collected in seven days. Secondary outcomes included the effect rate of UAS7 being reduced to 14 or below during follow-ups, Symptom Check List 90 (SCL90), Dermatology Life Quality Index (DLQI), and serum IgE level. Patients were instructed to document everyday UAS score one week before treatment till the end of follow-up at week eight. SCL90 and DLQI scores were collected before treatment, once a week during the treatment phase and at the end of weeks five and eight during followup. Serum IgE level tests were conducted before and at the end of treatment phase. The trial measurements were unchanged after trial commencement. The trial physicians or therapists performed active surveillance of side effects and adverse events from baseline to five weeks using the Adverse Events Surveillance Form, which were reported in this study. We also monitored compliance using a Patient Compliance Form. Adverse events and compliance were monitored and cross-checked against the patient's clinical notes.

2.8. Statistical Analysis. We compared the effective rates after treatment phase (week four, UAS7 $\leq 7$ ) and at the end of follow-ups (weeks five and eight, UAS7 $\leq 14$ ) among groups by using $\chi^{2}$ test $(\alpha=0.05)$ and performed multiple comparisons between groups with adjusted $\left.\alpha^{\prime}\left(\alpha^{\prime}=\alpha /(2(k-1))\right), \quad \alpha^{\prime}=0.0125\right)$. In this part, we conducted both the intention-to-treat analysis and the perprotocol analysis and dealt with the missing values of dropout or lost-to-follow-up cases by method of last observation carried forward (LOCF). In addition, in the analyses of scores of UAS7, SCL90, and DLQI, we performed linear mixed effects models in the intention-to-treat analysis and variance analysis for repeated measurements in the perprotocol analysis. Adverse events were presented descriptively. Two statisticians blinded to the treatment group independently carried out the intention-to-treat analyses and per-protocol analyses with a software package SPSS (version 18.0).

\section{Results and Discussion}

3.1. Patients. Figure 1 summarizes the trial group assignments, loss to follow-up, treatment completion, and protocol deviations. Of the 458 patients assessed for eligibility, 174 underwent randomization. In total, 170 randomized patients were started on the treatment and were included in the intention-to-treat analysis and safety description. Of these, 140 patients who went through the trial without protocol violation were included in the per-protocol analysis. Table 2 shows the baseline characteristics of participants. We did not consider any differences between the treatment groups to be relevant.

3.2. Outcomes. The effective rates (UAS7 $\leq 7)$ at the end of treatment phase (week four) were significantly different among the three groups $\left(\chi^{2}=13.308, P=0.001\right)$, which were 


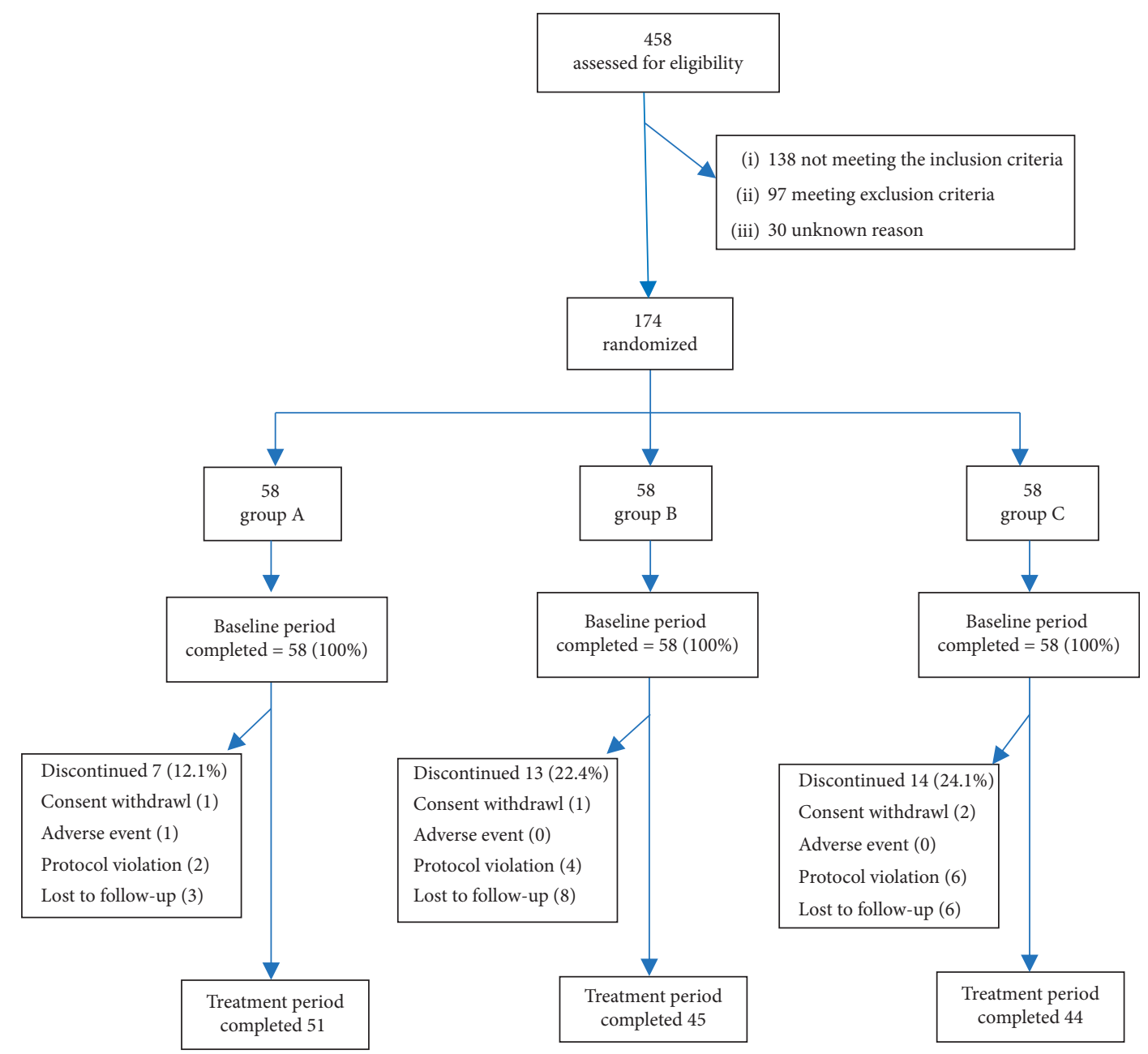

FIGURE 1: Flowchart showing trial group assignments, loss to follow-up, and treatment completion.

TABLE 2: Baseline characteristics of participants.

\begin{tabular}{|c|c|c|c|c|c|}
\hline & $\begin{array}{c}\mathrm{A} \\
n=58\end{array}$ & $\begin{array}{c}\mathrm{B} \\
n=58\end{array}$ & $\begin{array}{c}\mathrm{C} \\
n=58\end{array}$ & Kruskal-Wallis $\mathrm{H}$ test & Fisher's exact test \\
\hline Age $($ mean $(\mathrm{SD}))$ & $39.83(1.88)$ & $40.57(1.91)$ & $40.62(1.91)$ & $P=0.979$ & \\
\hline Course (mean $(\mathrm{SD}))$ & $16.78(1.18)$ & $13.88(1.26)$ & $13.91(1.25)$ & $P=0.111$ & \\
\hline Sex (male/female (\%)) & $\begin{array}{c}19 / 39 \\
(32.8 / 67.2)\end{array}$ & $\begin{array}{c}11 / 47 \\
(19.0 / 81.0)\end{array}$ & $\begin{array}{c}11 / 47 \\
(19.0 / 81)\end{array}$ & & $P=0.163$ \\
\hline
\end{tabular}

$73.7 \%$ in group A, $45.6 \%$ in group B, and $42.9 \%$ in group C. Multiple analysis indicated significant differences between groups $\mathrm{A}$ and $\mathrm{B}\left(\chi^{2}=9.330, P=0.004\right)$ and groups $\mathrm{A}$ and $C\left(\chi^{2}=11.050, P=0.001\right)$ and no significant difference between groups $\mathrm{B}$ and $\mathrm{C}\left(\chi^{2}=0.087, P=0.850\right)$. The effective rates (UAS7 $\leq 14$ ) during the follow-up periods were as follows: at the end of week five, significant difference was observed among the three groups $\left(\chi^{2}=11.059, P=0.004\right)$, that is, $73.7 \%$ in group $\mathrm{A}, 43.9 \%$ in group $\mathrm{B}$, and $51.8 \%$ in group $\mathrm{C}$; at the end of week eight, the effective rates were $61.4 \%$ in group A, $22.8 \%$ in group B, and $21.4 \%$ in group C, also with significant difference among the three groups $(\chi 2=25.621, P<0.001)$. Results of further multiple comparisons were similar to those of week four (Table 3). Results of the per-protocol analysis were in consistency with those of the intention-to-treat analysis (Table 4).

In the linear mixed effects models analyses, the hypothesis tests of the selected repeated measurement structure met the requirements and the results converged, indicating that the models were reasonable (Table 5). Analysis results indicated that treatment effects were statistically significant in all UAS7, SCL90, and DLQI scores (Table 6). UAS7 pairwise comparisons showed that significant differences between groups $\mathrm{A}$ and $\mathrm{B}$ occurred at weeks five $(-10.76,95 \% \mathrm{CI}(-14.05,-7.47), P<0.001)$ and eight $(-15.51,95 \% \mathrm{CI}(-18.15,-13.76), P<0.001)$, and that significant differences between groups $\mathrm{A}$ and $\mathrm{C}$ occurred at weeks four $(-4.36,95 \% \mathrm{CI}(-7.68,-1.044), P=0.010)$, five 
TABle 3: Primary outcomes of treatment groups and treatment comparisons (ITTA*).

\begin{tabular}{lccccccc}
\hline Outcomes & Group A & Group B & Group C & \multicolumn{2}{c}{$\chi^{2}$ test ${ }^{* *}$} & \multicolumn{3}{c}{ Multiple comparison*** } \\
& $n=57(\%)$ & $n=47(\%)$ & $n=56(\%)$ & $(P$ value $)$ & $\begin{array}{c}\text { A\&B } \\
\text { A\&C }(P \text { value })\end{array}$ & $\begin{array}{c}\chi^{*}(P \text { value }) \\
\chi^{2}(P \text { value })\end{array}$ \\
\hline Week 4 & 42 & 26 & 24 & 13.308 & 9.330 & 11.050 \\
UAS7 $\leq 7$ & $(73.7)$ & $(45.6)$ & $(42.9)$ & $(0.001)$ & $(0.004)$ & $(0.001)$ & $(0.850)$ \\
Week 5 & 42 & 25 & 29 & 11.059 & 10.462 & 5.800 & 0.711 \\
UAS7 $\leq 14$ & $(73.7)$ & $(43.9)$ & $(51.8)$ & $(0.004)$ & $(0.002)$ & $(0.020)$ & $(0.454)$ \\
Week 8 & 35 & 13 & 12 & 25.621 & 17.417 & 18.581 & 0.031 \\
UAS7 $\leq 14$ & $(61.4)$ & $(22.8)$ & $(21.4)$ & $(<0.001)$ & $(<0.001)$ & $(<0.001)$ & $(1.000)$ \\
\hline
\end{tabular}

${ }^{*}$ Intention-to-treat analysis; ${ }^{* *}$ bilateral, $\alpha=0.05 ;{ }^{* * *}$ bilateral $\alpha^{\prime}=0.0125$.

TABle 4: Primary outcomes of treatment groups and treatment comparisons ( $\left.\mathrm{PPA}^{*}\right)$.

\begin{tabular}{|c|c|c|c|c|c|c|c|}
\hline \multirow[b]{2}{*}{ Outcomes } & \multirow[b]{2}{*}{ Group A, $n=51(\%)$} & \multirow[b]{2}{*}{ Group B, $n=45(\%)$} & \multirow[b]{2}{*}{ Group C, $n=44(\%)$} & \multirow{2}{*}{$\begin{array}{l}\chi^{2} \text { test }{ }^{* *} \\
(P \text { value })\end{array}$} & \multicolumn{3}{|c|}{ Multiple comparison $^{* * *}$} \\
\hline & & & & & $\begin{array}{c}\mathrm{A} \& \mathrm{~B} \\
\chi 2(P \text { value })\end{array}$ & $\begin{array}{c}\text { A\&C } \\
\chi^{2}(P \text { value })\end{array}$ & $\begin{array}{c}\text { B\&C } \\
\chi 2(P \text { value })\end{array}$ \\
\hline Week 4 & 38 & 21 & 19 & 11.596 & 7.824 & 9.659 & 0.109 \\
\hline UAS7 $\leq 7$ & $(74.5)$ & $(46.7)$ & $(44.2)$ & $(0.003)$ & $(0.007)$ & $(0.003)$ & $(0.832)$ \\
\hline Week 5 & 37 & 15 & 18 & 16.827 & 14.809 & 9.701 & 0.547 \\
\hline UAS7 $\leq 14$ & $(72.5)$ & $(33.3)$ & $(40.9)$ & $(<0.001)$ & $(<0.001)$ & $(0.003)$ & $(0.515)$ \\
\hline Week 8 & 30 & 3 & 1 & 52.277 & 20.829 & 34.362 & 1.001 \\
\hline $\mathrm{UAS} 7 \leq 14$ & $(58.8)$ & $(6.7)$ & $(2.3)$ & $(<0.001)$ & $(<0.001)$ & $(<0.001)$ & $(0.616)$ \\
\hline
\end{tabular}

${ }^{*}$ Per-protocol analysis; ${ }^{* *}$ bilateral, $\alpha=0.05 ;{ }^{* * *}$ bilateral $\alpha^{\prime}=0.0125$.

TABLE 5: Estimation of covariance parameters in linear mixed effects models.

\begin{tabular}{|c|c|c|c|c|c|c|c|c|}
\hline \multirow{2}{*}{ Dependent variable } & \multirow{2}{*}{\multicolumn{2}{|c|}{ Parameter }} & \multirow{2}{*}{ Estimation } & \multirow{2}{*}{ SD } & \multirow{2}{*}{ Wald Z } & \multirow{2}{*}{$P$} & \multicolumn{2}{|c|}{$95 \% \mathrm{CI}$} \\
\hline & & & & & & & Lower limit & Upper limit \\
\hline \multirow{2}{*}{ UAS7 } & Repeated & CS diagonal offset & 53.88 & 2.82 & 19.11 & $<0.01$ & 48.62 & 59.69 \\
\hline & Measurement & CS covariance & 34.22 & 4.95 & 6.91 & $<0.01$ & 24.51 & 43.92 \\
\hline \multirow{2}{*}{ SCL90 } & Repeated & CS diagonal offset & 47.57 & 2.50 & 19.05 & $<0.01$ & 42.92 & 52.73 \\
\hline & Measurement & CS covariance & 145.88 & 17.07 & 8.55 & $<0.01$ & 112.41 & 179.35 \\
\hline \multirow{2}{*}{ DLQI } & Repeated & CS diagonal offset & 6.97 & 0.36 & 19.11 & $<0.01$ & 6.30 & 7.72 \\
\hline & Measurement & CS covariance & 4.71 & 0.67 & 7.01 & $<0.01$ & 3.39 & 6.02 \\
\hline
\end{tabular}

Table 6: Fixed effects tests of linear mixed effects models.

\begin{tabular}{|c|c|c|c|c|c|}
\hline Dependent variable & Source of covariance & Numerator degrees of freedom & Denominator degrees of freedom & $\mathrm{F}$ & $P$ \\
\hline \multirow{6}{*}{ UAS7 } & Intercept & 1 & 485.497 & 0.146 & 0.702 \\
\hline & Group & 2 & 488.671 & 2.946 & 0.054 \\
\hline & Time & 1 & 759.500 & 0.005 & 0.943 \\
\hline & Group " time & 2 & 764.056 & 40.204 & $<0.001$ \\
\hline & Baseline & 1 & 482.538 & 6.224 & 0.013 \\
\hline & Time ${ }^{*}$ baseline & 1 & 755.909 & 4.599 & 0.032 \\
\hline \multirow{6}{*}{ SCL90 } & Intercept & 1 & 245.446 & 14.624 & $<0.001$ \\
\hline & Group & 2 & 244.683 & 2.892 & 0.057 \\
\hline & Time & 1 & 743.885 & 0.001 & 0.976 \\
\hline & Group * time & 2 & 741.350 & 8.357 & $<0.001$ \\
\hline & Baseline & 1 & 245.657 & 532.742 & $<0.001$ \\
\hline & Time ${ }^{*}$ baseline & 1 & 744.661 & 1.406 & 0.236 \\
\hline \multirow{6}{*}{ DLQI } & Intercept & 1 & 470.664 & 1.953 & 0.163 \\
\hline & Group & 2 & 475.203 & 2.165 & 0.116 \\
\hline & Time & 1 & 760.496 & 4.718 & 0.030 \\
\hline & Group ${ }^{*}$ time & 2 & 764.635 & 20.116 & $<0.001$ \\
\hline & Baseline & 1 & 470.404 & 179.695 & $<0.001$ \\
\hline & Time ${ }^{*}$ baseline & 1 & 763.768 & 0.720 & 0.397 \\
\hline
\end{tabular}


$(-8.92,95 \% \mathrm{CI}(-12.22,-5.62), P<0.001)$, and eight $(-16.41$, 95\%CI $(-19.06,-13.76), P<0.001)$. No significant difference in UAS7 was observed between groups B and C at all time periods (Table 7). Scores of SCL90 differed significantly between groups A and B from weeks one to eight $(P<0.05)$, except week four $(P=0.058)$, and between groups $A$ and $C$ at all time periods $(P<0.01$, Table 8$)$. Significant differences in DLQI occurred only at weeks five and eight between groups $\mathrm{A}$ and $\mathrm{B}$ and groups $\mathrm{A}$ and $\mathrm{C}(P<0.001$, Table 9$)$. In the per-protocol analysis, data before treatment were taken as covariates, and the results of variance analysis of repeated measurements were consistent with those of linear mixed effects models in the intention-to-treat analysis (Figure 2).

Serum IgE levels did not differ significantly among the three groups before and after treatment (Table 10).

3.3. Adverse Events. Six patients (3.53\%, $n=170)$ had drowsiness during the treatment period and were advised to take ebastine before sleep. One patient $(0.59 \%, n=170)$ in group A had dizziness after the initial two times of bloodletting therapy and discontinued the trial voluntarily. No other adverse events were observed.

3.4. Principal Findings. In this study on patients with CIU, four weeks of combined treatment with bloodletting therapy (acupoint pricking and cupping) and ebastine was clinically beneficial compared with combined treatment with placebo treatment (acupoint pseudopricking and cupping) and ebastine and single treatment with ebastine, which manifested at both the end of treatment phase and follow-ups. The secondary analyses supported this finding. No severe bloodletting therapy-related adverse event was observed.

3.5. Clinical Relevance. CIU is a common and debilitating allergic condition; however, its pathogenesis is yet unknown, and the treatment is tenuous. In this trial, a second-generation $\mathrm{H} 1$-antihistamine, ebastine, was prescribed as the first remedy. The effective rate of ebastine was $42.9 \%$ at week four and was $51.8 \%$ at week five; nonetheless, the effective rate was only $21.8 \%$ at week eight, proximate to that of the previous study, reflecting the weakness of second-generation $\mathrm{H} 1$-antihistamine in the long-term control of CIU. Previous studies on CIU, conducted over three and twelve months, reported that approximately $65 \%$ of the patients treated with $10 \mathrm{mg}$ ebastine experienced major improvement at the end of treatment according to the global patient/physician ratings $[28,29]$. Different response standard and medication period may lead to different response rate in this trial. There is general agreement regarding the use of higher doses of second-generation antihistamines as a second-step therapy in patients with severe, recalcitrant CIU for whom the standard dose is not effective. However, this agreement is mainly supported by isolated clinical studies. British guidelines give a grade $\mathrm{B}$ for the recommendation to use higher doses of antihistamines [10]. Likewise, Japanese guidelines give a recommendation level B-C1 and an evidence level II, V for increasing the dose of antihistamines up to twice the recommended amount when no response is achieved at standard doses [30]. In contrast, American guidelines agree that the data are limited and conflicting regarding the recommendation of up-dosing antihistamines for patients who are not responsive to standard doses [31]. A meta-analysis finds no differences in wheal number or response rates, and only significant differences with respect to the control of pruritus, with a low improvement magnitude ( 0.13 on a scale of $0-3)$ [8]. In brief, we should be cautious about up-dosing antihistamines and further high-quality studies on up-dosing are really needed.

In this study, bloodletting therapy combined with ebastine showed better curative effects from the other two groups for medium to severe CIU (baseline UAS7 $\geq 28$ ) at end of treatment phase and follow-ups, which were $73.7 \%$ at weeks four (UAS7 $\leq 7$ ) and five (UAS7 $\leq 14$ ), and a remaining $61.4 \%$ at week eight (UAS7 $\leq 14$ ), respectively, with significantly lower UAS7 score at weeks one and four after treatment termination but without severe adverse effect. It may provide positive solution to refractory CIU cases which do not respond to standard doses of second-generation H1-antihistamines. Notably, no differences were detected between groups $\mathrm{B}$ and $\mathrm{C}$, indicating that cupping was merely an operation that helped bloodletting rather than an effective manipulation in symptom control, while bleeding was the crucial procedure.

Bloodletting therapy help reduce the disease activity on the aspects of severity and recurrence frequency, both of which are directly related to the improvement of the psychological status (SCL90) and life quality (DQLI). Stress is an independent factor in the development and exacerbation in CIU, and bloodletting therapy on Sihua points (the combination of Geshu and Danshu points) has been proved to be effective in the treatment of general anxiety disorder [20]. We observed significant difference of SCL90 prior to the occurrence of significant difference of UAS7 between groups. Presumably, the improvement in SCL90 by bloodletting on Sihua points is beneficial to the alleviation of CIU symptom, forming a virtuous circle. Another beneficial factor needed consideration is patient education. Despite not being included in the intervention plan, the concepts of the complexity of CIU pathology and myriad causes and the importance of avoidance were relayed to the patients through natural physician-patient communication. This might be the missing link in the CIU management algorithm in guidelines.

CIU is an inflammatory disease [32, 33], where histamine plays a key role, but one of the players in a much complex disease. A previous study observed elevated interferon- $\gamma$ (IFN- $\gamma$ ) level and lowered interleukin 4 (IL-4) and IgE levels in CU patients treated with Back-Shu point acupuncture combined with pricking and cupping therapy and presumed that the therapy might correct the Th1/Th2 imbalance and reduce mast cell activation, thereby improving the CIU symptoms [34]. In addition, bloodletting therapy is shown to alleviate CIU by reducing serous leukotriene B4 (LTB4) and prostaglandin D2 (PGD2) levels [25]. Ear bloodletting therapy can reduce the expression level of interleukin-17 (IL-17) and interleukin-23 (IL-23) 
TABle 7: Means of UAS7 and treatment comparisons for all time periods.

\begin{tabular}{|c|c|c|c|c|c|c|c|c|c|}
\hline \multirow[b]{2}{*}{ Time } & \multicolumn{2}{|c|}{ Group A } & \multicolumn{2}{|c|}{ Group B } & \multicolumn{2}{|c|}{ Group C } & \multicolumn{3}{|c|}{ Pairwise comparison* } \\
\hline & $\mathrm{N}$ & Mean (SD) & $\mathrm{N}$ & Mean (SD) & $\mathrm{N}$ & Mean (SD) & $\begin{array}{c}\mathrm{A}-\mathrm{B}(95 \% \mathrm{CI}) \\
P \text { value }\end{array}$ & $\begin{array}{c}\mathrm{A}-\mathrm{C}(95 \% \mathrm{CI}) \\
P \text { value }\end{array}$ & $\begin{array}{c}\text { B-C }(95 \% \mathrm{CI}) \\
P \text { value }\end{array}$ \\
\hline Baseline & 58 & $\begin{array}{l}34.29 \\
(0.80) \\
\end{array}$ & 58 & $\begin{array}{l}32.48 \\
(0.73) \\
\end{array}$ & 58 & $\begin{array}{l}32.72 \\
(0.72) \\
\end{array}$ & & & \\
\hline Week 1 & 57 & $\begin{array}{c}14.37 \\
(10.46)\end{array}$ & 57 & $\begin{array}{l}14.90 \\
(9.58)\end{array}$ & 56 & $\begin{array}{l}14.89 \\
(9.88)\end{array}$ & $\begin{array}{c}-1.52 \\
(-5.08,2.03) \\
0.400 \\
\end{array}$ & $\begin{array}{c}-1.404 \\
(-4.98,2.17) \\
0.493 \\
\end{array}$ & $\begin{array}{c}0.12 \\
(-3.43,3.67) \\
0.948 \\
\end{array}$ \\
\hline Week 2 & 57 & $\begin{array}{c}11.51 \\
(8.82)\end{array}$ & 52 & $\begin{array}{l}11.52 \\
(9.48)\end{array}$ & 49 & $\begin{array}{l}12.92 \\
(9.59)\end{array}$ & $\begin{array}{c}-0.70 \\
(-4.14,2.75) \\
0.691 \\
\end{array}$ & $\begin{array}{c}-1.78 \\
(-5.26,1.70) \\
0.315 \\
\end{array}$ & $\begin{array}{c}-1.08 \\
(-4.64,2.47) \\
0.549 \\
\end{array}$ \\
\hline Week 3 & 53 & $\begin{array}{c}9.55 \\
(8.11)\end{array}$ & 50 & $\begin{array}{l}10.04 \\
(8.94)\end{array}$ & 45 & $\begin{array}{l}11.22 \\
(8.91)\end{array}$ & $\begin{array}{c}-1.05 \\
(-4.41,2.30) \\
0.536 \\
\end{array}$ & $\begin{array}{c}-2.05 \\
(-5.48,1.38) \\
0.239 \\
\end{array}$ & $\begin{array}{c}-1.00 \\
(-4.47,2.48) \\
0.571 \\
\end{array}$ \\
\hline Week 4 & 51 & $\begin{array}{l}6.765 \\
(6.03)\end{array}$ & 45 & $\begin{array}{c}9.43 \\
(9.04)\end{array}$ & 44 & $\begin{array}{l}10.91 \\
(9.05)\end{array}$ & $\begin{array}{c}-2.98 \\
(-6.28,0.338) \\
0.078 \\
\end{array}$ & $\begin{array}{c}-4.36 \\
(-7.68,-1.044) \\
0.010\end{array}$ & $\begin{array}{c}-1.38 \\
(-4.80,2.02) \\
0.422 \\
\end{array}$ \\
\hline Week 5 & 51 & $\begin{array}{l}11.63 \\
(8.98)\end{array}$ & 45 & $\begin{array}{l}21.33 \\
(8.91)\end{array}$ & 44 & $\begin{array}{l}19.77 \\
(8.20)\end{array}$ & $\begin{array}{c}-10.76 \\
(-14.05,-7.47) \\
<0.001\end{array}$ & $\begin{array}{c}-8.92 \\
(-12.22,-5.62) \\
<0.001\end{array}$ & $\begin{array}{c}1.84 \\
(-1.56,5.23) \\
0.286 \\
\end{array}$ \\
\hline Week 8 & 51 & $\begin{array}{l}15.29 \\
(9.53)\end{array}$ & 45 & $\begin{array}{l}29.49 \\
(7.04)\end{array}$ & 44 & $\begin{array}{l}30.61 \\
(6.36)\end{array}$ & $\begin{array}{c}-15.51 \\
(-18.15,-13.76) \\
<0.001\end{array}$ & $\begin{array}{c}-16.41 \\
(-19.06,-13.76) \\
<0.001\end{array}$ & $\begin{array}{c}-0.90 \\
(-3.62,1.83) \\
0.516\end{array}$ \\
\hline
\end{tabular}

*Based on estimated marginal means.

TABLE 8: Means of SCL90 and treatment comparisons for all time periods.

\begin{tabular}{|c|c|c|c|c|c|c|c|c|c|}
\hline \multirow[b]{2}{*}{ Time } & \multicolumn{2}{|c|}{ Group A } & \multicolumn{2}{|c|}{ Group B } & \multicolumn{2}{|c|}{ Group C } & \multicolumn{3}{|c|}{ Pairwise comparison*A } \\
\hline & $\mathrm{N}$ & Mean (SD) & $\mathrm{N}$ & Mean (SD) & $\mathrm{N}$ & Mean (SD) & $\begin{array}{c}\text { A-B }(95 \% \mathrm{CI}) \\
P \text { value }\end{array}$ & $\begin{array}{c}\mathrm{A}-\mathrm{C}(95 \% \mathrm{CI}) \\
P \text { value }\end{array}$ & $\begin{array}{c}\mathrm{B}-\mathrm{C}(95 \% \mathrm{CI}) \\
P \text { value }\end{array}$ \\
\hline Baseline & 58 & $\begin{array}{l}128.21 \\
(4.07)\end{array}$ & 58 & $\begin{array}{l}120.86 \\
(4.00)\end{array}$ & 58 & $\begin{array}{l}121.09 \\
(3.93)\end{array}$ & & & \\
\hline Week 1 & 57 & $\begin{array}{l}116.90 \\
(25.38)\end{array}$ & 57 & $\begin{array}{l}115.83 \\
(29.82)\end{array}$ & 56 & $\begin{array}{l}117.98 \\
(28.17)\end{array}$ & $\begin{array}{c}-4.50 \\
(-8.56,-0.43) \\
0.030\end{array}$ & $\begin{array}{c}-6.10 \\
(-10.18,-2.03) \\
0.004\end{array}$ & $\begin{array}{c}-1.61 \\
(-5.67,-2.45) \\
0.435\end{array}$ \\
\hline Week 2 & 57 & $\begin{array}{l}113.60 \\
(24.19)\end{array}$ & 52 & $\begin{array}{l}114.25 \\
(30.39)\end{array}$ & 49 & $\begin{array}{l}115.16 \\
(26.31)\end{array}$ & $\begin{array}{c}-4.85 \\
(-9.55,-0.14) \\
0.044 \\
\end{array}$ & $\begin{array}{c}-7.28 \\
(-12.07,-2.48) \\
0.003 \\
\end{array}$ & $\begin{array}{c}-2.43 \\
(-7.31,2.44) \\
0.326 \\
\end{array}$ \\
\hline Week 3 & 53 & $\begin{array}{l}110.68 \\
(22.92)\end{array}$ & 50 & $\begin{array}{l}110.64 \\
(26.54)\end{array}$ & 45 & $\begin{array}{l}115.89 \\
(28.41)\end{array}$ & $\begin{array}{c}-5.56 \\
(-10.78,-0.33) \\
0.037 \\
\end{array}$ & $\begin{array}{c}-10.69 \\
(-16.06,-5.33) \\
<0.001 \\
\end{array}$ & $\begin{array}{c}-5.14 \\
(-10.55,0.274) \\
0.063 \\
\end{array}$ \\
\hline Week 4 & 51 & $\begin{array}{l}109.61 \\
(28.00)\end{array}$ & 45 & $\begin{array}{l}1110.07 \\
(26.37)\end{array}$ & 44 & $\begin{array}{l}116.02 \\
(28.41)\end{array}$ & $\begin{array}{c}-5.37 \\
(-10.93,0.194) \\
0.058 \\
\end{array}$ & $\begin{array}{c}-11.96 \\
(-17.56,-6.37) \\
<0.001 \\
\end{array}$ & $\begin{array}{c}-6.60 \\
(-12.33,-0.86) \\
0.025 \\
\end{array}$ \\
\hline Week 5 & 51 & $\begin{array}{l}109.20 \\
(22.51)\end{array}$ & 45 & $\begin{array}{l}111.33 \\
(27.93)\end{array}$ & 44 & $\begin{array}{l}116.25 \\
(27.34)\end{array}$ & $\begin{array}{c}-7.31 \\
(-12.71,-1.922) \\
0.008 \\
\end{array}$ & $\begin{array}{c}-12.58 \\
(-18.00,-7.15) \\
<0.001 \\
\end{array}$ & $\begin{array}{c}-5.26 \\
(-10.83,0.30) \\
0.063 \\
\end{array}$ \\
\hline Week 8 & 51 & $\begin{array}{c}109.00 \\
(222.51)\end{array}$ & 45 & $\begin{array}{l}111.82 \\
(32.36)\end{array}$ & 44 & $\begin{array}{l}115.91 \\
(32.64)\end{array}$ & $\begin{array}{c}-8.29 \\
(-15.52,-1.47) \\
0.018\end{array}$ & $\begin{array}{c}-12.61 \\
(-19.48,-5.74) \\
<0.001\end{array}$ & $\begin{array}{c}-4.31 \\
(-11.36,2.73) \\
0.228\end{array}$ \\
\hline
\end{tabular}

*Based on estimated marginal means.

[35] and the expression level of prostaglandin E2 (PGE2), thromboxane B2 (TXB2), leukotriene B4 (LTB4), and 6keto-prostaglandin F1- $\alpha$ (6-k-PGF1- $\alpha$ ) [36] in patients with eczema. However, we did not detect similar changes in the
IgE level among groups. Further research is needed on the effective mechanism of bloodletting therapy in treating CIU. Immunomodulatory mechanisms as well as stress-related mechanisms may provide new perspective. 
TABLE 9: Means of DLQI and treatment comparisons for all time periods.

\begin{tabular}{|c|c|c|c|c|c|c|c|c|c|}
\hline \multirow[b]{2}{*}{ Time } & \multicolumn{2}{|c|}{ Group A } & \multicolumn{2}{|c|}{ Group B } & \multicolumn{2}{|c|}{ Group C } & \multicolumn{3}{|c|}{ Pairwise comparison* } \\
\hline & $\mathrm{N}$ & Mean (SD) & $\mathrm{N}$ & Mean (SD) & $\mathrm{N}$ & Mean (SD) & $\begin{array}{c}\text { A-B }(95 \% \mathrm{CI}) \\
P \text { value }\end{array}$ & $\begin{array}{c}\text { A-C }(95 \% \mathrm{CI}) \\
P \text { value }\end{array}$ & $\begin{array}{c}\text { B-C }(95 \% \mathrm{CI}) \\
P \text { value }\end{array}$ \\
\hline Baseline & 58 & $\begin{array}{l}11.46 \\
(0.84)\end{array}$ & 58 & $\begin{array}{c}9.64 \\
(0.86)\end{array}$ & 58 & $\begin{array}{c}9.64 \\
(0.84)\end{array}$ & & & \\
\hline Week 1 & 57 & $\begin{array}{c}7.18 \\
(5.64)\end{array}$ & 57 & $\begin{array}{c}5.79 \\
(5.33)\end{array}$ & 56 & $\begin{array}{c}5.93 \\
(4.58)\end{array}$ & $\begin{array}{c}0.12 \\
(-1.01,1.26) \\
0.832\end{array}$ & $\begin{array}{c}-0.02 \\
(-1.17,1.12) \\
0.970\end{array}$ & $\begin{array}{c}-0.14 \\
(-1.28,1.00) \\
0.802\end{array}$ \\
\hline Week 2 & 57 & $\begin{array}{c}5.54 \\
(4.67)\end{array}$ & 52 & $\begin{array}{c}4.89 \\
(5.35)\end{array}$ & 49 & $\begin{array}{c}5.14 \\
(4.72)\end{array}$ & $\begin{array}{c}-0.19 \\
(-1.51,1.12) \\
0.772\end{array}$ & $\begin{array}{c}-0.46 \\
(-1.80,0.88) \\
0.497\end{array}$ & $\begin{array}{c}-0.27 \\
(-1.62,1.09) \\
0.698\end{array}$ \\
\hline Week 3 & 53 & $\begin{array}{c}4.76 \\
(4.44)\end{array}$ & 50 & $\begin{array}{c}4.10 \\
(4.69)\end{array}$ & 45 & $\begin{array}{c}4.64 \\
(4.50)\end{array}$ & $\begin{array}{c}-0.30 \\
(-1.58,0.99) \\
0.650\end{array}$ & $\begin{array}{c}-0.69 \\
(-2.01,0.63) \\
0.306\end{array}$ & $\begin{array}{c}-0.39 \\
(-1.72,0.94) \\
0.562\end{array}$ \\
\hline Week 4 & 51 & $\begin{array}{c}4.9 \\
(3.94)\end{array}$ & 45 & $\begin{array}{c}2.87 \\
(3.83)\end{array}$ & 44 & $\begin{array}{c}4.16 \\
(4.36)\end{array}$ & $\begin{array}{c}-0.77 \\
(-0.53,2.06) \\
0.245\end{array}$ & $\begin{array}{c}-0.48 \\
(-17.80,0.82) \\
0.466\end{array}$ & $\begin{array}{c}-1.25 \\
(-2.57,0.08) \\
0.066\end{array}$ \\
\hline Week 5 & 51 & $5.28(4.13)$ & 45 & $\begin{array}{c}5.98 \\
(4.73)\end{array}$ & 44 & $\begin{array}{c}6.11 \\
(4.78)\end{array}$ & $\begin{array}{c}-1.82 \\
(-3.08,-0.55) \\
0.005 \\
-3.54 \\
(-4.54,-2.54) \\
<0.001\end{array}$ & $\begin{array}{c}-1.81 \\
(-3.08,-0.55) \\
0.005 \\
-4.40 \\
(-5.40,-3.40) \\
<0.001\end{array}$ & $\begin{array}{c}0.00 \\
(-1.29,1.30) \\
0.998 \\
-0.86 \\
(-1.88,0.16) \\
0.099\end{array}$ \\
\hline
\end{tabular}

* Based on estimated marginal means.

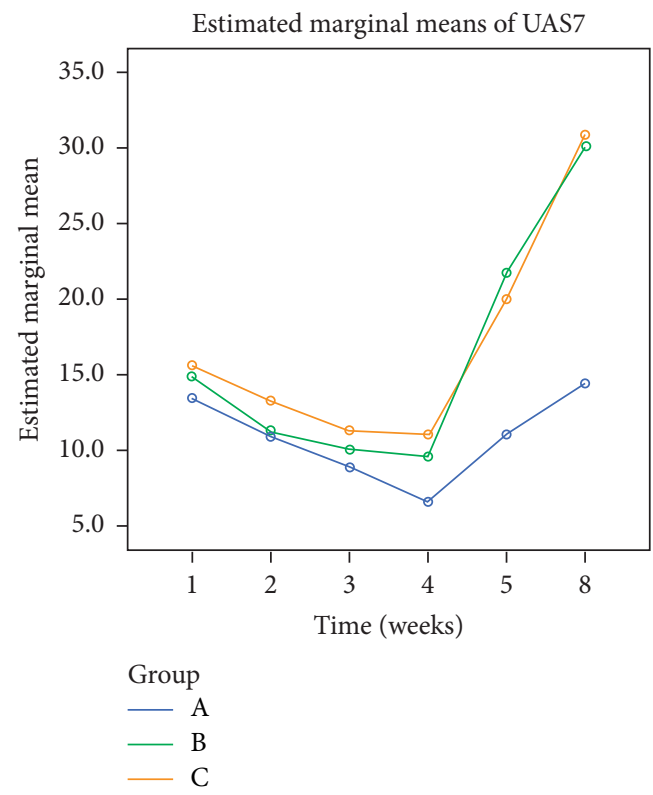

(a)



(b)

Figure 2: Continued. 




(c)

FIgURE 2: Profile of time and grouping factors.

TABle 10: Serum IgE levels before and after treatment.

\begin{tabular}{lcccc}
\hline IgE & Group A & Group B & Group C & K-Wallis H test \\
\hline \multirow{2}{*}{ Baseline } & 222.50 & 354.78 & 350.35 & $P=0.515$ \\
& $(60.97)$ & $(219.98)$ & $(207.54)$ & $P=0.552$ \\
\multirow{2}{*}{ Week 4 } & 228.17 & 342.84 & 330.87 & $(189.00)$ \\
& $(64.61)$ & $(183.26)$ & & \\
\hline
\end{tabular}

3.6. Limitations. Nevertheless, the present study has some limitations. The main limitation was that we could not rule out the possibility that some patients administered additional drugs or avoided ebastine without informing us, which might influence the difference in outcomes between the treatment groups. In order to reduce this problem, we encouraged the patients to register the drugs in patients' notes and give us a genuine record of medication and symptom evaluation. Secondly, this was a single-centre trial, and participants had a propensity for complementary methods, and we enrolled patients who had endured only two years of the disease, which may cause sampling bias.

\section{Conclusions}

Bloodletting therapy is an effective and safe complementary treatment in CIU. Further studies should focus on the underlying mechanism and large-scale multicentre standard control for its general applicability.

\section{Data Availability}

The data used in this paper are available upon reasonable request from the corresponding author.

\section{Disclosure}

The funders had no part in planning, performing, or reporting of the trial.

\section{Conflicts of Interest}

The authors declare that there are no conflicts of interest regarding the publication of this paper.

\section{Acknowledgments}

The funding was granted by the Guangdong Science and Technology Department (grant number: 2016A020215194).

\section{References}

[1] T. Zuberbier, W. Aberer, R. Asero et al., "The EAACI/ GA2LEN/EDF/WAO guideline for the definition, classification, diagnosis, and management of urticaria: the 2013 revision and update," Allergy, vol. 69, no. 7, pp. 868-887, 2014.

[2] M. Maurer, K. Weller, C. Bindslev-Jensen et al., "Unmet clinical needs in chronic spontaneous urticaria. A GA2LEN task force report1," Allergy, vol. 66, no. 3, pp. 317-330, 2011. 
[3] M. Maurer, P. Staubach, U. Raap et al., "H1-antihistaminerefractory chronic spontaneous urticaria: it's worse than we thought - first results of the multicenter real-life AWARE study," Clinical \& Experimental Allergy, vol. 47, no. 5, pp. 684-692, 2017.

[4] M. Maurer, P. Staubach P, U. Raap et al., "ATTENTUS, a german online survey of patients with chronic urticaria highlighting the burden of disease, unmet needs and real-life clinical practice," British Journal of Dermatology, vol. 174, no. 4, pp. 892-894, 2017.

[5] M. Maurer, M. Abuzakouk, F. Bérard et al., "The burden of chronic spontaneous urticaria is substantial: real-world evidence from ASSURE-CSU," Allergy, vol. 72, no. 12, pp. 2005-2016, 2017.

[6] L. K. DeLong, S. D. Culler, S. S. Saini et al., "Annual direct and indirect health care costs of chronic idiopathic urticaria: a cost analysis of 50 nonimmunosuppressed patients," Archives of Dermatology, vol. 144, no. 1, pp. 35-39, 2008.

[7] B. F. O’Donnell, "Urticaria: impact on quality of life and economic cost," Immunology and Allergy Clinics of North America, vol. 34, no. 1, pp. 89-104, 2014.

[8] S. Guillén-Aguinaga, I. Jáuregui Presa, E. Aguinaga-Ontoso, F. Guillén-Grima, and M. Ferrer, "Updosing nonsedating antihistamines in patients with chronic spontaneous urticaria: a systematic review and meta-analysis," British Journal of Dermatology, vol. 175, no. 6, pp. 1153-1165, 2016.

[9] F. Humphreys and J. A. A. Hunter, "The characteristics of urticaria in 390 patients," British Journal of Dermatology, vol. 138, no. 4, pp. 635-638, 1998.

[10] R. J. Powell, S. C. Leech, S. Till, P. A. J. Huber, S. M. Nasser, and A. T. Clark, "BSACI guideline for the management of chronic urticaria and angioedema," Clinical \& Experimental Allergy, vol. 45, no. 3, pp. 547-565, 2015.

[11] A. Picardi and D. Abeni, "Stressful life events and skin diseases: disentangling evidence from myth," Psychotherapy and Psychosomatics, vol. 70, no. 3, pp. 118-136, 2001.

[12] T. C. Theoharides, L. K. Singh, W. Boucher et al., "Corticotropin-releasing hormone induces skin mast cell degranulation and increased vascular permeability, a possible explanation for its proinflammatory effects*," Endocrinology, vol. 139, no. 1, pp. 403-413, 1998.

[13] S. M. Dyke, B. S. Carey, and E. R. Kaminski, "Effect of stress on basophil function in chronic idiopathic urticaria," Clinical Experimental Allergy, vol. 38, pp. 86-92, 2008.

[14] T. C. Theoharides, J. M. Donelan, N. Papadopoulou, J. Cao, D. Kempuraj, and P. Conti, "Mast cells as targets of corticotropin-releasing factor and related peptides," Trends in Pharmacological Sciences, vol. 25, no. 11, pp. 563-568, 2004.

[15] N. Papadopoulou, D. Kalogeromitros, N. G. Staurianeas, D. Tiblalexi, and T. C. Theoharides, "Corticotropin-releasing hormone receptor-1 and histidine decarboxylase expression in chronic urticaria," Journal of Investigative Dermatology, vol. 125, no. 5, pp. 952-955, 2005.

[16] M. Özkan, S. B. Oflaz, N. Kocaman et al., "Psychiatric morbidity and quality of life in patients with chronic idiopathic urticaria," Annals of Allergy, Asthma \& Immunology, vol. 99, no. 1, pp. 29-33, 2007.

[17] P. Staubach, M. Dechene, M. Metz et al., "High prevalence of mental disorders and emotional distress in patients with chronic spontaneous urticaria," Acta Dermato-Venereologica, vol. 91, no. 5, pp. 57-61, 2011.

[18] C. Torresani, S. Bellafiore, and G. De Panfilis, "Chronic urticaria is usually associated with fibromyalgia syndrome," Acta Dermato Venereologica, vol. 89, no. 4, pp. 389-392, 2009.
[19] P. Staubach, A. Eckhardt-Henn, M. Dechene et al., "Quality of life in patients with chronic urticaria is differentially impaired and determined by psychiatric comorbidity," British Journal of Dermatology, vol. 154, no. 2, pp. 294-298, 2006.

[20] H. Ma, K. Yu, Y. Li et al., "Bloodletting therapy combined with paroxetine hydrochloride for generalized anxiety disorder: randomized controlled trial," in Proceedings of IEEE International Conference on Bioinformatics and Biomedicine, IEEE, Shanghai, China, pp. 174-176, December 2013.

[21] L. Gao and W. Yuan, "study on ancient literature of correlation between urticaria and external infection of six evil factors," Chinese Journal of Information on TCM, vol. 22, no. 3, pp. 10-13, 2015.

[22] Q. Li, "Thirty-six cases of chronic urticaria treated by bloodletting and cupping," Chinese Journal of Convalescent Medicine, vol. 22, no. 8, pp. 710-711, 2013.

[23] X. Liao and J. Wang, "Therapeutic observation of bloodletting at quchi (LI 11) for chronic urticaria due to wind-heat," Shanghai Journal of Acupuncture and Moxibustion, vol. 35, no. 11, pp. 1323-1325, 2016.

[24] K. Lv, L. Zheng, and Z. Liu, "Observation on therapeutic efficacy of bloodletting puncture and cupping combined with cetirizine hydrochloride in the treatment of chronic urticaria," Chinese Journal of Dermatovenereolgy of Integrated Traditional and Western Medicine, vol. 5, no. 4, pp. 225-226, 2006.

[25] P. Wu, W. Ma, and X. Zhao, "Observation on Therapeutic efficacy of skin acupuncture combined with cupping on 30 cases of chronic urticaria," Guiding Journal of Traditional Chinese Medicine and Pharmacology, vol. 16, no. 11, p. 79, 2010.

[26] Na Zhao, "Clinical study of bloodetting puncture and cupping in the treatment of chronic urticaria," M.S. thesis, Hunan University of Traditional Chinese Medicine, Changsha, China, 2013.

[27] Y. Liang, G. Zhang, and H. Wen, "Clinical observations on the efficacy of total glucosides of paeony combined with ebastine in the treatment of chronic idiopathic urticaria," Chinese Journal of Dermatology, vol. 46, no. 8, pp. 588-590, 2013.

[28] R.-P. Rorer, "A long-term (one-year) safety and efficacy phase III study of ebastine $(10 \mathrm{mg})$ in the treatment of chronic urticaria in adult patients (study EBA 020)," Report no.: RP64305-020. 82, Antony Cedex (France): Rhône-Poulenc Rorer, SA, Antony, France, July.

[29] B. Kalis, "Double-blind multicentre comparative study of ebastine, terfenadine and placebo in the treatment of chronic idiopathic urticaria in adults," Drugs, vol. 52, no. 1, pp. 30-34, 1996.

[30] M. Hide and T. Hiragun, "Japanese guidelines for diagnosis and treatment of urticaria in comparison with other countries," Allergology International, vol. 61, no. 4, pp. 517-527, 2012.

[31] J. A. Bernstein, D. M. Lang, D. A. Khan et al., "The diagnosis and management of acute and chronic urticaria: 2014 update," Journal of Allergy and Clinical Immunology, vol. 133, no. 5, pp. 1270-1277, 2014.

[32] A. B. Kay, P. Clark P, M. Maurer et al., "Elevations in T-helper-2-initiating cytokines (interleukin-33, interleukin25 and thymic stromal lymphopoietin) in lesional skin from chronic spontaneous ("idiopathic") urticaria," British Journal of Dermatology, vol. 172, no. 4, pp. 294-1302, 2015.

[33] S. Ying, Y. Kikuchi, Q. Meng, A. B. Kay, and A. P. Kaplan, "TH1/TH2 cytokines and inflammatory cells in skin biopsy specimens from patients with chronic idiopathic urticaria: comparison with the allergen-induced late-phase cutaneous reaction," Journal of Allergy and Clinical Immunology, vol. 109, no. 4, pp. 694-700, 2002. 
[34] J. Li, H. Liu, Di . Chen et al., "Back-shu point Acupuncture combined with pricking and cupping therapy in treating chronic urticaria and its influences on serum IL-4, IFN- $\lambda$, Ig E levels," Chinese General Practice, vol. 14, no. 10A, pp. 32923294, 2011.

[35] Z. Gong, Z. Luo, W. Xie et al., "Effect of ear bloodletting therapy on the expression of IL -17 and IL-23 in patients with eczema," Journal of Emergency in Traditional Chinese Medicine, vol. 24, no. 7, pp. 1249-1251, 2015.

[36] Z. Gong, D. Li, J. Yang et al., "Effect of ear bloodletting therapy on the expression of PGE2, TXB2, LTB4 and 6-kPGF1 $\alpha$ in patients with eczem," Nei Mongol Journal of Traditional Chinese Medicine, vol. 36, no. 1, pp. 51-52, 2017. 